
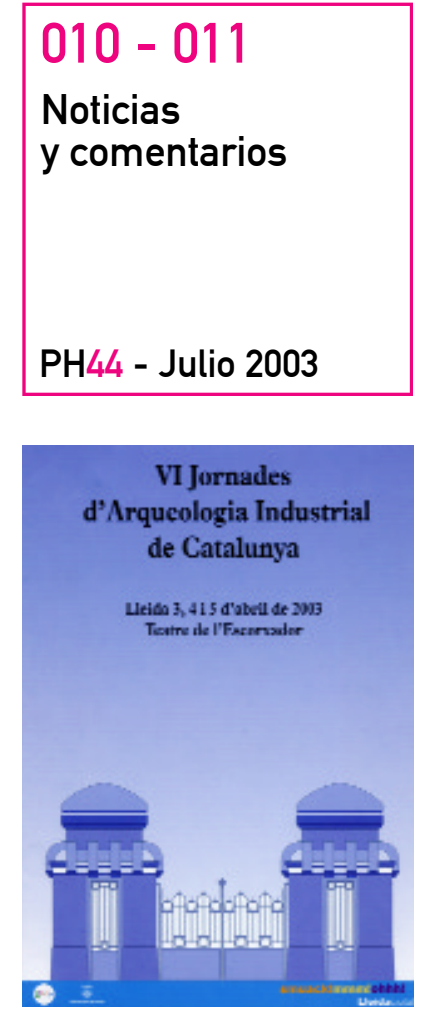

$2^{\circ}$ CONGRESO INTERNACIONAL SOERE FORTIFICACIONES

COCNSI, RVACIOLN Y 1) I I U S I O N DE ENTORNOS FORTIFICAADOS

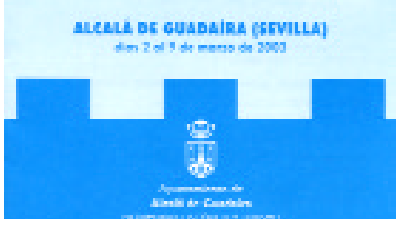

\title{
Las VI Jornadas de Arqueología Industrial de Cataluña giraron en torno a la industria agroalimentaria
}

Las VI Jornadas de Arqueología Industrial de Cataluña, celebradas en Lérida del 3 al 5 de abril de 2003, tuvieron como tema central la industria agroalimentaria y las industrias auxiliares que se han configurado a su alrededor: maquinaria y sistemas de producción. Paralelamente fueron tratados otros aspectos del patrimonio industrial, como la industria del agua -especialmente los canales de riego-, los métodos de investigación y estudio, y las actuaciones de preservación y salvaguarda y difusión de este patrimonio.

Desde la Asociación del Museo de la Ciencia y de la Técnica y de Arqueología Industrial de Cataluña, organizadora de las Jornadas, se reconoce que en el encuentro se ha confirmado la vinculación entre transformación industrial y economía, así como la dependencia, en muchas ocasiones, del patrimonio industrial respecto del urbanismo y la política del suelo. Para conocer y rehabilitar el patrimonio industrial -se ha concluido- es necesario conocer sus sistemas productivos y la maquinaria que lo llevó a cabo como un todo, sin desgajarse y trocearse; es decir, salvar un edificio industrial comporta también salvar in situ, si existe, su maquinaria, su contenido. En ocasiones, al vaciar los edificios, quedan mutilados, y al trasladar sus bienes muebles, estos quedan igualmente descontextualizados, sin memoria de lugar.

Otra de los hechos destacables en el panorama actual es la existencia de grupos de profesionales que estudian a fondo y documentan el patrimonio industrial. Al mismo tiempo, en las VI Jornadas se ha puesto de relieve la importancia de rescatar el patrimonio oral del patrimonio industrial (aún hay personas -muy mayores- que con sus experiencias complementan una parte fundamental de este pa- trimonio y que, en algunas ocasiones, gracias a sus explicaciones, se pueden reconstruir elementos industriales: telares, bombas...). Ese testimonio de la industria, que parece estar el último de la fila, sigue siendo un eslabón indispensable para la cadena de recuperación del patrimonio de la industria.

El desarraigo y la dificultad de algunos casos actuales del patrimonio industrial en peligro también se puso de manifiesto, específicamente a través del caso del silo del puerto de Málaga, construcción sólida de cemento armado, en muy buenas condiciones y de fácil reutilización. Todos los asistentes, 120 personas, estuvieron de acuerdo por unanimidad en que este elemento emblemático del patrimonio industrial malagueño no debía desaparecer, sino que se tenía que reconvertir para que con sus nuevos usos la ciudadanía de Málaga disfrutase de lo que fue un elemento activo de su industria.

Se comentó además cómo se estaba haciendo oídos sordos respecto a la situación del depósito de aguas de Salamanca, edificio destruido, aunque fue un elemento patrimonial de la ciudad y hubo muchas muestras de apoyo para su recuperación. Hay que estar vigilante, también, sobre otro edificio emblemático, la fábrica Bayer de Barcelona.

Más información:

AMCTAIC

associaciomct@eic.ictnet.es

Asunción Feliu-Torras

Vicepresidenta de la AMCTAIC- Barcelona

\section{Problemas actuales y nuevos enfoques para la protección del patrimonio fortificado}

Las conclusiones extraídas del II Congreso sobre Fortificaciones, celebrado en Alcalá de Guadaíra entre los días 3 y 9 de marzo, han llevado a los especialistas a tomar decisiones acerca del tratamiento del patrimonio fortificado.

Tanto en las sesiones científicas como durante las visitas se pudo comprobar cómo el conjunto de los entornos fortificados (y no ya el mero edificio que suele simbolizar a la fortificación) presenta una amplia problemática referida a su conservación, puesta en valor y posterior difusión. A procesos históricos de abandono, destrucción o fagocitación por entornos urbanos, se une una indefinición legal que en algunos casos perdura hasta la actualidad.
Es el caso de numerosos castillos de la provincia de Sevilla (como el mismo de Alcalá de Guadaíra u otros de la Sierra Norte), cuya titularidad aún reside en el Concejo sevillano, mientras que su administración y gestión han de correr por cuenta de los municipios en los que se enclavan.

Como aportaciones principales del Congreso destaca una serie de ideas que no por menos conocidas han de dejar de repetirse hasta que encuentren eco social y administrativo:

> La necesidad de un conocimiento riguroso (histórico, arqueológico, medioambiental) como paso previo al desarrollo de políticas de conservación y difusión social. 
> Las administraciones han de implicarse en la conservación del Patrimonio fortificado andaluz. La tutela patrimonial no ha de limitarse a operaciones de salvamento cuyo carácter intrínsecamente coyuntural no permite acciones más sostenidas. Por ello, urge establecer criterios que prioricen las acciones y los entornos a intervenir, bajo la óptica de que la conservación integral es imposible ante el mero volumen numérico de nuestro Patrimonio.

$>$ En línea con lo anterior, es necesario establecer criterios administrativamente tutelados referentes a los programas de rehabilitación y restauración. La dejación de la tutela ha propiciado (y lo sigue haciendo) actuaciones incontroladas que atentan claramente contra los valores paisajísticos, estéticos e históricos protegidos por la Ley, en pro de un utilitarismo o una apuesta por el "diseño" escasamente justificables.

> Finalmente, hay que plantearse qué relación queremos que exista entre nuestro Patrimonio fortificado y las tendencias sociales y económicas actuales. Hoy dia la disyuntiva se sitúa entre un conservacionismo públicamente sufragado, que no termina de encontrar una línea clara de actuación, y una adaptación al "mercado turistico" que suele conllevar una apuesta por lo económicamente rentable en detrimento de lo que no lo es. A este respecto, el debate sigue abierto, pero son las administraciones las que han de velar por la conservación y el respeto a la legislación vigente.

En definitiva, los temas tratados han permitido poner de manifiesto la importancia del papel de las administraciones locales, auténticas gestoras de los entornos fortificados. Es a nivel local donde se sitúan los principales problemas: gestión de los exiguos recursos económicos, compatibilización del desarrollo (urbano, industrial) y la conservación patrimonial, difusión social de un Patrimonio muchas veces incluso desconocido por la ciudadanía, etcétera. La mayor parte de estas situaciones tienen una clara vertiente paisajística y relacionada con el planeamiento urbano. Es por ello que pensamos que éste será un argumento a discutir y desarrollar en los próximos años.

\section{Fernando Amores Carredano}

Enrique Luis Dominguez Berenjeno

Coordinadores científicos

Laura Ballesteros Núñez

Concejala Delegada de Patrimonio Histórico

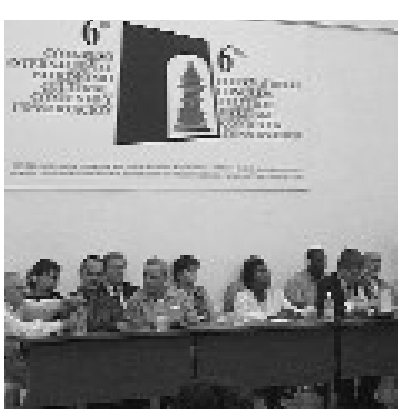

\section{Numerosos especialistas defienden la cooperación internacional en el último congreso del CENCREM}

El sexto Congreso Internacional Patrimonio Cultural: Contexto y Conservación, celebrado en la sede del Centro Nacional de Conservación, Restauración y Museología (CENCREM) de La Habana, contó con un número considerable de especialistas de diversos paises y áreas geográficas, convirtiéndose en marco propicio para el intercambio de experiencias entre los delegados, la creación de bases para la colaboración internacional y la formación de redes especializadas. El resultado de este encuentro fue muy positivo, gracias a la presentación de variados trabajos de interés y actualidad científica, técnica y cultural.

Esta sexta edición del congreso, que tuvo lugar entre el 14 y el 18 de abril, contó con la asistencia de 142 profesionales del sector provenientes de 24 paises europeos, latinoamericanos y norteamericanos. La delegación de Cuba estuvo integrada por 66 especialistas de todo el país.

En el transcurso del evento se realizaron tres Conferencias Magistrales: El Centro Histórico de La Habana Vieja y su rescate, por Eusebio Leal Spengler; La arquitectura como exégesis de la memoria, impartida por el arquitecto Gamal Michelén, crítico de arte y ex viceministro de Cultura de la República Dominicana; y El reto ho- landés, presentada por Rik Vos, director del Instituto Holandés de Patrimonio Cultural.

El trabajo del Congreso se estructuró en tres comisiones donde se presentaron 105 ponencias en exposición oral, y una sesión de pósters en la que se mostraron 40 trabajos que permitieron el intercambio directo de experiencias con sus autores.

La primera comisión debatió 40 trabajos sobre conservación preventiva; materiales, técnicas y procedimientos para la conservación de los bienes muebles; rescate y conservación de sitios arqueológicos y manejo del patrimonio cultural subacuático. La segunda se dedicó a valorar 29 trabajos sobre restauración y rehabilitación arquitectónica; patrimonio industrial y patrimonio del siglo XX: medio ambiente y patrimonio cultural; patrimonio natural: gestión medioambiental y planeamiento cultural y centros y sitios históricos. La tercera analizó 36 trabajos acerca de turismo, patrimonio cultural e identidad; patrimonio cultural: economías e informática y sobre enseñanza, formación y patrimonio cultural.

El Congreso incluyó una jornada de visitas técnicas con cuatro recorridos, que tuvieron en cuenta los diversos intereses de los participantes. El próximo encuentro tendrá lugar en 2005. 